\title{
Supplementary feeding of the reintroduced Red Kite (Milvus milvus) in UK gardens
}

Article

Published Version

Creative Commons: Attribution 3.0 (CC-BY)

Orros, M. E. and Fellowes, M. D. E. (2014) Supplementary feeding of the reintroduced Red Kite (Milvus milvus) in UK gardens. Bird Study, 61 (2). pp. 260-263. ISSN 0006-3657 doi: https://doi.org/10.1080/00063657.2014.885491 Available at https://centaur.reading.ac.uk/35674/

It is advisable to refer to the publisher's version if you intend to cite from the work. See Guidance on citing.

To link to this article DOI: http://dx.doi.org/10.1080/00063657.2014.885491

Publisher: Taylor \& Francis

All outputs in CentAUR are protected by Intellectual Property Rights law, including copyright law. Copyright and IPR is retained by the creators or other copyright holders. Terms and conditions for use of this material are defined in the End User Agreement.

www.reading.ac.uk/centaur

\section{CentAUR}


Central Archive at the University of Reading

Reading's research outputs online 
This article was downloaded by: [University of Reading]

On: 07 April 2014, At: 07:25

Publisher: Taylor \& Francis

Informa Ltd Registered in England and Wales Registered Number: 1072954 Registered office: Mortimer House, 37-41 Mortimer Street, London W1T 3J H, UK

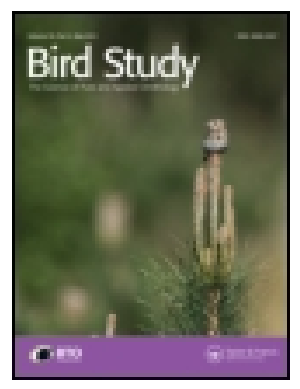

\title{
Bird Study
}

Publication details, including instructions for authors and subscription information:

http:// www. tandfonline.com/loi/tbis20

\section{Supplementary feeding of the reintroduced Red Kite Milvus milvus in UK gardens}

\author{
Melanie E. $\operatorname{Orros}^{a} \&$ Mark D. E. Fellowes $^{a}$ \\ a People and Wildlife Research Group, School of Biological Sciences, University of Reading, \\ Reading RG6 6AS, UK \\ Published online: 05 Mar 2014.
}

To cite this article: Melanie E. Orros \& Mark D. E. Fellowes (2014): Supplementary feeding of the reintroduced Red Kite Milvus milvus in UK gardens, Bird Study, DOI: 10.1080/00063657.2014.885491

To link to this article: http:// dx. doi.org/ 10.1080/00063657.2014.885491

\section{PLEASE SCROLL DOWN FOR ARTICLE}

Taylor \& Francis makes every effort to ensure the accuracy of all the information (the "Content") contained in the publications on our platform. Taylor \& Francis, our agents, and our licensors make no representations or warranties whatsoever as to the accuracy, completeness, or suitability for any purpose of the Content. Versions of published Taylor \& Francis and Routledge Open articles and Taylor \& Francis and Routledge Open Select articles posted to institutional or subject repositories or any other third-party website are without warranty from Taylor \& Francis of any kind, either expressed or implied, including, but not limited to, warranties of merchantability, fitness for a particular purpose, or non-infringement. Any opinions and views expressed in this article are the opinions and views of the authors, and are not the views of or endorsed by Taylor \& Francis. The accuracy of the Content should not be relied upon and should be independently verified with primary sources of information. Taylor \& Francis shall not be liable for any losses, actions, claims, proceedings, demands, costs, expenses, damages, and other liabilities whatsoever or howsoever caused arising directly or indirectly in connection with, in relation to or arising out of the use of the Content.

This article may be used for research, teaching, and private study purposes. Any substantial or systematic reproduction, redistribution, reselling, loan, sub-licensing, systematic supply, or distribution in any form to anyone is expressly forbidden. Terms $\&$ Conditions of access and use can be found at http:// www.tandfonline.com/page/terms-and-conditions

Taylor \& Francis and Routledge Open articles are normally published under a Creative Commons Attribution License http://creativecommons.org/licenses/by/3.0/. However, authors may opt to publish under a Creative Commons Attribution-Non-Commercial License http://creativecommons.org/licenses/by-nc/3.0/ Taylor \& Francis and Routledge Open Select articles are currently published under a license to publish, which is based upon the Creative Commons Attribution-Non-Commercial No-Derivatives License, but allows for text and data mining of work. Authors also have the option of publishing an Open Select article under the Creative Commons Attribution License http://creativecommons.org/licenses/by/3.0/.

It is essential that you check the license status of any given Open and Open Select article to confirm conditions of access and use. 


\title{
Supplementary feeding of the reintroduced Red Kite Milvus milvus in UK gardens
}

\author{
MELANIE E. ORROS* and MARK D. E. FELLOWES \\ People and Wildlife Research Group, School of Biological Sciences, University of Reading, Reading RG6 6AS, UK
}

\begin{abstract}
Capsule The provision of meat for garden birds is unusual in the UK but a reintroduced raptor, the Red Kite Milvus milvus, is now regularly fed in some areas. A questionnaire of garden kite feeders revealed that people were most often motivated to feed by a desire to see kites close up and that most provisioning falls within available guidelines. We estimated the median amount of food thought to be taken by kites per kite-feeding garden per day as $21 \mathrm{~g}$, sufficient to support 0.12-0.26 individuals.
\end{abstract}

Approximately half of UK households feed wild birds in their gardens (Davies et al. 2009). Although omnivorous species such as Magpies Pica pica are common in and around gardens, provisioning generally targets passerines with predominantly granivorous diets (Toms 2003, Cannon et al. 2005). However, meat is now known to be provided by householders in and around the Chiltern Hills ('the Chilterns') in SE England (Carter \& Whitlow 2005, Killick 2006, Orros \& Fellowes, unpubl. data). Their target is a scavenging raptor of conservation concern, the Red Kite Miluus milvus (Linnaeus, 1758; Accipitridae), following its successful local reintroduction as part of a national programme that started in 1989 (Carter 2007).

Despite recent work indicating that the extent of garden feeding of kites can be considerable $[10 \%$ of 100 Chilterns village residents (specific location data lacking; Killick 2006) and 4.5\% households in the Greater Reading urban conurbation of 96000 households (Orros \& Fellowes, unpubl. data)], no data have been published on further details of the activity. In Killick's (2006) unpublished report, the ten kite feeders provided left-overs, processed meats and small animal carcasses. All but one gave under $1 \mathrm{~kg}$ each time and did not feed daily.

The lack of published data on garden feeding of kites is surprising. The Red Kite is of conservation concern and has attracted much attention since its reintroduction. Providing meat for garden birds is unusual in a national

*Corresponding author. Email: melorros@yahoo.com context and the activity itself has become controversial. For example, two authors of kite feeding guidelines for the public (Anon 2006) no longer support such feeding [RSPB (J. Knott pers. comm. 2013); Chilterns Conservation Board (www.chilternsaonb.org/aboutchilterns/red-kites/red-kite-faqs)].

Various concerns have been raised although published evidence is lacking. Carter (2007) outlined these: (1) cooked foods have been suggested to have minimal nutritional value; (2) additives in processed meat such as salt may be harmful; (3) calcium deficiencies have been linked to growth and bone disorders in some young kites by vets and therefore meat lacking skin and/or bone has also been a concern; (4) garden feeding may be partly responsible for the kites' slow spread since their reintroduction.

Given these concerns and the high levels of garden feeding mentioned above coupled with the lack of data, we conducted a UK-wide survey of Red Kite feeders. Our aims were to examine feeders' provisioning habits and motivations, estimate the amounts of food taken and therefore the numbers of kites supported per garden and to compare the activity recorded with available feeding guidance (Table 1).

The questionnaire covered length, season and frequency of feeding, amounts and types of food and the proportion believed taken by kites, and feeders' motivations (Supplementary Appendix S1). We did not mention the feeding guidelines because of concerns that this might influence responses. To maximise sample size, the questionnaire was online 
Table 1. Summary of the elements of the guidance/advice on Red Kite Milvus milvus supplementary feeding assessed here, indicating the publication(s) mentioning them and the percentage of respondents from SE England ( $n=114)$ complying with each element.

\begin{tabular}{lcc}
\hline Guidance given & Included in & \% of respondents complying \\
\hline Nature of food provided & & $78(42 \%$ only this; $36 \%$ some $)$ \\
State/imply food should contain skin and bone & $1-4$ & $77^{\mathrm{c}}$ \\
Do not provide processed meats/state these may be harmful & $1-4$ & 19 \\
Feed whole small mammal carcasses & $1-3^{\mathrm{a}}$ & 2,4 \\
Avoid cooked meat & 1 & $80(49 \%$ only raw; $31 \%$ some $)$ \\
Do not feed roadkill (may have been poisoned) & 1,4 & 97 \\
Nature of provisioning activity & $1-3$ & $80^{\mathrm{d}}(49 \% \leq 200 \mathrm{~g} ; 31 \% \leq 400 \mathrm{~g})$ \\
Provide small amounts (not quantified) & 4 & $81^{\mathrm{e}}$ \\
Remove remaining food at end of day & $88^{f}$
\end{tabular}

Notes: 1 = ZSL (2006): guidelines for landowners, 2 = Anon (2006): guidelines for the public. See text for details of withdrawal of support by two authors, 3 = Carter (2007, p. 123): book on the Red Kite. Note that these are described as a summary of (2) but were included here as feeders may access only one of these, 4 = Carter \& Whitlow (2005); booklet on Red Kites in the Chilterns.

'(3) States 'food derived from complete animal carcasses' but does not specify small mammals.

${ }^{b}$ Also implied by (1) and (3) as the food described in these is unlikely to be cooked.

cProvision of processed meats and/or kitchen scraps assumed to represent non-compliance.

dPercentage who estimated masses.

ePercentage who stated that not all food was eaten by kites $(n=77)$. Of those not complying, only one respondent stated that all such food was left out and the rest reported 'a combination' of being eaten by other species and left uneaten.

'This percentage did not feed daily. We acknowledge that less frequent feeding may still be regular.

(Bristol Online Surveys; paper copies on request) and advertised nationally, particularly in reintroduction areas, from October 2011 to July 2012. We included former kite feeders to investigate why households had stopped feeding.

We used the season and frequency of feeding to calculate the estimated days per year on which each household provided food ('annual feeding days'). For frequency categories without a single numerical value, we assumed $1.5 /$ week for 'once or twice a week', 4/week for 'several times a week' and once every two months for 'less often [than monthly]'. We then used the annual feeding days to estimate the proportion of current feeders providing food on any given day [Prop day: overall mean of estimated days/year kites fed $\div 365$ for each garden].

We calculated the approximate mass taken by kites on each feeding day for each garden from feeders' estimates of amounts provided and proportions that kites took. Midpoints of mass ranges provided were used except for the open-ended maximum category, for which the lower limit $(1 \mathrm{~kg})$ was used. For the proportions thought taken by kites, we assumed 0.75 for 'over half, 0.25 for 'under half and 0.1 for 'only a small amount'.

This mass was then multiplied by the annual feeding days to give the mass thought taken per year for each garden. From this, we calculated the daily median mass per garden $\left(M_{\text {pergarden }}\right)$. We used the mass believed taken by kites as a more conservative estimate than all food provided. The median was used to minimise the effects of outliers.

Valid responses were received from 108 current and 21 former kite feeders (those who had fed only inadvertently or for under one month were excluded). We pooled current and former feeders' answers except for the calculations of Prop day and $M_{\text {pergarden }}$ for which we used only current feeders to provide more up-to-date values.

We note that the sample is small and that interested individuals may have been more likely to participate. However, we advertised widely over several months and respondents encompassed a broad spectrum, from those feeding daily to a few times a year. As an indication, the percentage of kite feeders provisioning monthly or less (28\%) is similar to that for feeders of other garden birds across five UK cities (36\%: Gaston et al. 2007).

Most responses came from SE England (current feeder $n=95$; former $n=19$ ), within or close to the Chilterns. Our institution borders this region and local interest makes it probable that survey coverage was greatest here. However, the geographical bias also fits with the region's history of kite feeding (Carter \& Whitlow 2005; Killick 2006), the time since the local reintroduction (beginning 1989), and the number of breeding pairs being around one third of the UK total (Welsh Kite Trust 2011). As a rough indication of coverage, 25 current feeders surveyed here lived within Greater Reading, the study area of our previous work 
(Orros \& Fellowes, unpubl. data). In that study, a survey of a representative cross-section of households with $1 \%$ coverage found 43 kite feeders, implying approximately $0.6 \%$ coverage here.

A further geographical factor is that supplementary provisioning has been discouraged around some kite reintroductions since they began (e.g. http://www. yorkshireredkites.net/). Levels may therefore be lower and people less likely to 'admit' to feeding in these areas. Given these factors, we present only the SE England responses below and in Table 1.

Fifty-three per cent of these respondents described themselves as rural residents and 97\% fed other wild birds. Seventy-five per cent usually saw kites locally more than once a day. Surprisingly, $8 \%$ saw kites fewer than two or three times a month yet still provided food. The most common duration of feeding was 1-2 years $(28 \%$ respondents), with 3\% feeding for over 10 years and $11 \%$ for five months or less. Sixty-one per cent fed year-round. Overall, $12 \%$ fed daily but feeding less than monthly and once or twice a week were most common (24\% and $23 \%$, respectively). Chicken was given by $74 \%$, by far the most common of the 12 food categories reported (data not shown). The next most common category, beef/lamb/ pork, was given by significantly fewer respondents (48\%; two-tailed test of two proportions $P<0.001$ ) even though these meats were only merged for analysis.

The amounts given were typically low, with $80 \%$ of those who estimated masses giving $\leq 400 \mathrm{~g}$ each time (Table 1 ). $\mathrm{M}_{\text {pergarden }}$ was $21 \mathrm{~g} /$ day/garden for current feeders [Q1-Q3: 6-64; mean $=91 \mathrm{~g}, n=83$ (some respondents did not provide an estimate of the masses of food provided and/or of the frequency at which they fed and therefore $M_{\text {pergarden }}$ could not be calculated for these households)]. This would support 0.12-0.26 kites [minimum and maximum daily energy requirement estimates $=80$ and $180 \mathrm{~g}$, respectively (Carter 2007)]. Prop day $=0.28$ (95\% CI: 0.18-0.39) and therefore on any given day most feeders do not provide food. Although both $M_{\text {pergarden }}$ and Prop $_{\text {day }}$ are low, feeding may still represent a considerable resource if many households participate locally (e.g. 4350 over the $72-\mathrm{km}^{2}$ Greater Reading conurbation; Orros \& Fellowes, unpubl. data).

We assessed the levels of compliance with the available feeding guidance (Table 1). Over $75 \%$ of respondents met each of the recommendations to some extent except for the advice to feed small mammal carcasses (19\%). In our opinion, this relatively low value is likely to relate to ease of availability because such carcasses are sold by specialist pet-food retailers or are dependent upon cat- or trap-kills (36\% of those providing them). This may also explain the very high compliance (97\%) with the recommendation to avoid giving roadkill. Related to this, awareness of feeding guidelines may also play a role because purchasing carcasses or collecting roadkill are relatively specialist activities compared with simply giving meat. As mentioned above, we did not include questions on the guidelines and so could not investigate this possibility further.

In terms of motivations for feeding, most respondents fed kites to see them up close $(62 \%)$, with a desire to conserve them the next most common (48\%; multiple reasons permitted). Other popular reasons included photography and to use left-over food (both 29\%). All other answers were given by $\leq 5 \%$ of respondents.

Given the recent advice not to feed and 'negative' media on feeding, we were surprised at the prevalence of 'neutral' reasons for stopping feeding. A change in circumstances (e.g. moving house) was the most common (42\% of former feeders). Others included becoming aware of advice not to feed $(32 \%)$, concerns of over-reliance $(21 \%)$ and that other birds were scared away $(11 \%)$ (NB: free-text answers assigned to categories a posteriori). However, we note that our sample is very small $(n=19$, reporting 25 reasons) and that those stopping for 'neutral' reasons may have been more likely than others to participate.

We seek here neither to promote nor to discourage garden feeding of Red Kites but to provide baseline information on feeding rates to ascertain its potential importance for kite populations. We follow Carter's (2007, p. 123) view that if appropriate guidelines are followed, garden feeding in itself is 'unlikely to cause serious problems' and is in essence similar to provisioning other wild birds. As a cautionary note, amongst various effects on Spanish Griffon Vultures Gyps fulvus attributed to sudden closure of feeding stations were a halt in population growth and increased reports of cattle attacks and subsequent negative media (Margalida et al. 2010). Although resource availability changes are likely to be less problematic for dietary generalists such as kites, an ecological 'trap' (Schlaepfer et al. 2002) may result if substantial provisioning is halted, at least short-term. Although plentiful resources may exist in rural areas, as for the Chilterns (Carter \& Whitlow 2005), and kites are wide-ranging birds, alternative foods may be relatively scarce in urban areas if the findings of Orros \& Fellowes (unpubl. data) are typical. In that work, sufficient waste food and roadkill were recorded in Greater Reading to support only up to 30 kites from a daily population in the low hundreds even with unrealistic assumptions of daily replenishment and no competition. 
In conclusion, our results suggest that, based on the $21 \mathrm{~g}$ thought to be taken by kites per feeding garden per day, between four and nine of these gardens would be required to fully provision a single kite assuming full dependency on garden food. Further, most feeding complies with the available guidelines. We hope that these observations will inform future monitoring and guidance related to Red Kite garden feeding. Our finding that feeders are most often motivated by the opportunity to see kites at close range also hints at the value of garden feeding of wild animals in providing an accessible experience of wildlife to a human population increasingly disconnected from nature (Pyle 2003).

\section{ACKNOWLEDGEMENTS}

We are very grateful to all those who completed the survey and/or advertised it. The work was approved by the University of Reading's School of Biological Sciences Ethics Committee. Comments from the journal editor and two anonymous reviewers greatly improved the paper. The underlying research data for this article can be accessed by emailing m.fellowes@reading.ac.uk

\section{FUNDING}

M.O. was funded by a BBSRC doctoral training award.

\section{SUPPLEMENTAL DATA}

The questionnaire for Red Kite feeders (Supplementary Appendix S1) can be accessed http://dx.doi.org/10.1080/ 00063657.2014 .885491$.

\section{REFERENCES}

Anon. 2006. The effects of feeding reintroduced red kites in England and guidance on best practice. Chilterns Conservation Board, Natural England, RSPB, Southern England Kite Group, ZSL. Available from: http://web. onetel.com/ gerrywhitlow/sekg/kite\%20feeding\%20guidelines.pdf [accessed September 2013].

Cannon, A.R., Chamberlain, D.E., Toms, M.P., Hatchwell, B.J. \& Gaston, K.J. 2005. Trends in the use of private gardens by wild birds in Great Britain 1995-2002. J. Appl. Ecol 42: 659-671.

Carter, I. 2007. The Red Kite. Arlequin Press, Shrewsbury.

Carter, I. \& Whitlow, G. 2005. Red Kites in the Chilterns, 2nd edn. English Nature; Chilterns Conservation Board, Chinnor.

Davies, Z.G., Fuller, R.A., Loram, A., Irvine, K.N., Sims, V. \& Gaston, K.J. 2009. A national scale inventory of resource provision for biodiversity within domestic gardens. Biol. Conserv. 142: 761771.

Gaston, K., Fuller, R., Loram, A., MacDonald, C., Power, S. \& Dempsey, N. 2007. Urban domestic gardens (XI): variation in urban wildlife gardening in the United Kingdom. Biodivers. Conserv. 16: 3227-3238.

Killick, T. 2006. Is public feeding of the Red Kite (Milvus milvus) in the Chilterns AONB helping, or hindering their reintroduction? Unpublished Advanced Diploma Thesis. University of Oxford Department for Continuing Education, Oxford

Margalida, A., Donázar, J.A., Carrete, M. \& Sánchez-Zapata, J.A. 2010. Sanitary versus environmental policies: fitting together two pieces of the puzzle of European vulture conservation. J. Appl. Ecol. 47: 931-935.

Pyle, R. 2003. Nature matrix: reconnecting people and nature. Oryx 37: 206-214.

Schlaepfer, M.A., Runge, M.C. \& Sherman, P.W. 2002. Ecological and evolutionary traps. Trends Ecol. Evol. 17: 474-480.

Toms, M. 2003. The BTO/CJ Garden BirdWatch Book, British Trust for Ornithology, Thetford.

Welsh Kite Trust. 2011. The newsletter of the Welsh Kite Trust. Issue 26. Autumn 2011. Available from: http://www.welshkitetrust.org/ [accessed September 2013].

ZSL. 2006. Helping red kites. A good practice guide for landowners in England. Available from: http://static.zsl.org/files/red-kites-final279.pdf [accessed September 2013]. 